\title{
Fuzzy Logic Recommended Student Learning Levels
}

\author{
Abdul Rahman ${ }^{1}$, Destiarini², Joko Kuswanto ${ }^{3}$ \\ 1,2,3 Informatika, Fakultas Teknik dan Komputer, Universitas Baturaja \\ ${ }^{1}$ abdulrahman@ft.unbara.ac.id, ${ }^{2}$ destiarini1979@yahoo.co.id, ${ }^{3}$ ko.8515@gmail.com
}

\begin{abstract}
In the process of admitting students, the English course uses a learning level placement test. At the application stage the test encountered problems such as the slow pace of determining student learning levels based on paperbased test results. The purpose of this study is to provide recommendations for the level of student learning using the Fuzzy method. Where the level of learning English is divided into categories Foundation, Basic, Elementary, Intermediate and Advance. The input values are Listening, Vocabulary, Structure and Reading. The results of the study were tested for the accuracy of the dataset with the confusion matrix method with an accuracy of $88 \%$.
\end{abstract}

Keywords : student, learning levels, fuzzy logic, english course, confusion matrix

\section{INTRODUCTION}

English Language Courses and Training Institutions are held to meet the needs of the community in an effort to develop themselves in foreign language skills. In the registration process, there is a level placement test stage that determines a student's proficiency in English. In carrying out this activity, several problems were encountered, such as the slow pace of determining student learning levels based on paper-based test results, and the ineffective and inefficient process of determining student learning levels Sutrisno \& Budiyanto (2019).

Formal education is generally taken up by academic channels in schools ranging from the level of children's education to higher education. The education process in schools makes students as educational subjects that are educated and taught classically by teachers or educators with the aim of developing the potential that exists in students Rahman, Mutiarawan, Darmawan, Rianto, \& Syafrullah (2019).

This study applies the fuzzy method in providing appropriate and accurate learning level recommendations. In determining the level of student learning based on predetermined assessment criteria. Assessment can be defined as a systematic and continuous method for collecting, analyzing and using information from measured results to improve student learning in terms of knowledge acquired, understanding developed, and skills and competencies acquired Hameed (2017).

The rubric clearly states the educational objectives of the course / program / assignment and how the course learning objectives / criteria are met, to achieve the expected standards. Rubrics are designed and used to determine the value or level of achievement of the learning standards achieved by students. Bloom's taxonomy level is defined as the criterion for evaluating student performance Rao, Mangalwede, \& Deshmukh (2018).

The cognitive domain associated with the development of intellectual skills starts with the simplest level, remember, understand, then intermediate level analysis and application, finally the top level evaluates or makes. The affective domain deals with human emotions such as feelings, enthusiasm, attitudes, motivation, etc. From the simplest acceptance, responding to phenomena to judging, regulating values and finally internalizing values. Basically, the psychomotor domain deals with the use of motor skills such as physical movements and their coordination. These skills can be developed with practice and range from manual tasks such as writing on a blackboard to more complex tasks such as driving a car or dancing Rao et al. (2018).

We propose an evaluation model based on Fuzzy logic which is robust and also provides flexibility in the evaluation process. Professor L. A. Zadeh discovered the concept of Fuzzy Logic in 1964. He presented his first paper on fuzzy sets in 1965]. In 1974, Mamdani developed the first fuzzy logic controller used in predicting results when data is incorrect, unclear or some data is missing. Fuzzy controllers are widely used in weather forecasting, stock market, product market, health monitoring systems, aviation systems, temperature and pressure controllers in manufacturing industries etc. It is rulebased and reliable [4]. In this study, the learning level consists of five categories, namely Foundation, Basic, Elementary, Intermediate and Advance. To recommend the level of student learning using the fuzzy logic method. 


\section{LITERATURE REVIEW}

Assessment has the potential not only to measure and report on learning but also to promote it. Student assessment is an integral part of the learning experience and curriculum design. It is usually used to evaluate learning outcomes and provide the basis for individual student certification. Conventional scoring systems are based largely on human judgment, which tend to be subjective and have high rates of error and uncertainty. Because of the traditional stresses in assessments of objectivity, appropriateness, consistency and certainty and because of the trend of increasing class sizes and limited resources for teaching, examiners and lectures have always challenged their ability to provide timely and fair assessments. In order to overcome the aforementioned challenges, a need arises to explore innovation and technology to facilitate assessment and to include other dimensions, which cannot be considered in conventional assessment systems, to ensure and promote deep learning and critical thinking. In this paper presented a fuzzy scoring system, which takes into account the complexity, difficulty and importance of the exam questions, is presented. A simplified implementation of the type-2 interval fuzzy system using basic knowledge of the type-1 fuzzy is presented. A comparison between the use of a type-1 fuzzy system and a type- 2 interval in reducing uncertainty and providing a more transparent and fair assessment that can reflect individual student needs and developmental progress is presented Hameed (2016).

A new method how to evaluate and assess optical network links and finally, to find the optimal path. To test and prove the assumptions introduced in the article, data transport theory is combined and implemented into a simulation model. The simulation model demonstrates a new approach, optimizes existing optical links, and calculates the optimal path for transferring data. In order to process clear input parameter relationships, fuzzy logic is used to assess each link quality and utilization. To provide a comprehensive evaluation, several parameters are taken into account Cibira \& Dulik (2016).

Student performance evaluation using the Fuzzy Inference System (FIS) for the Network Analysis (NA) course is studied by the third semester of Electronics and Communication Engineering students. This paper describes the importance of Bloom's level in learning and developing critical thinking skills for NA courses and designs a scoring rubric by aligning the rubric's criteria with Bloom's taxonomy level that interns are given as input to the FIS. The five inputs that identify, understand, apply, analyze, and design / create are obscured using the Mamdani Fuzzy Inference System. With the help of fuzzy rules, the predicted results are expressed in terms of linguistic variables Rao et al. (2018).

Academic advice to students is a task that requires a lot of time, expertise and intellectual investment from academic experts. To help students find suitable decisions in a short period of time, this project implements a Smart Algorithm to design applications on smart phones. The proposed system is implemented and tested for validation with real data collected from valid students. The experimental results show that a system has a mean square root error of $6.64 \%$ and can thus be used successfully to identify the likelihood that enrolling for a course is the correct decision Aly, Eskaf, \& Selim (2017).

The absence of a computerized decision support system in determining the extension of the employee contract at PT. Graha Prima Perkasa so that the company experiences problems in determining the contract extension every period, to solve this problem a decision support system is created that uses the fuzzy logic of the mamdani method, fuzzy logic is one of the sciences that can analyze uncertainty, in this study using the fuzzy logic of the mamdani method. To get the output from this method, 4 stages are needed, namely; The formation of fuzzy sets, application of implication functions, composition of rules, defuzzification and the criteria used are attendance, achievement, discipline, and field implementation using dau or three linguistic values on each variable from the results of the research that has been done. The mamdani method can be used as a recommendation for the extension of the employee's work contract Efendi (2019).

\section{RESEARCH METHODS}

In this study, using data obtained from an English course agency. Existing data are used to determine the level of student learning according to the values obtained using the Fuzzy Logic method.

\section{Fuzzy Set Formation}

The determination of variables and the formation of fuzzy sets for each variable used are Listening, Vocabulary, Structure, and Reading. The fuzzy sets formed from each of these variables are as follows:

1. Listening Variables

The set of variables can be seen in Table 1 .

LISTENING FUZZY SET

\begin{tabular}{|c|c|}
\hline Linguistic Value & Value Range \\
\hline Low & $0-7$ \\
\hline Medium & $5-10$ \\
\hline Average & $8-14$ \\
\hline High & $12-16$ \\
\hline
\end{tabular}

The curve that is formed to determine the membership function of the foundation variables can be seen in Figure 1.

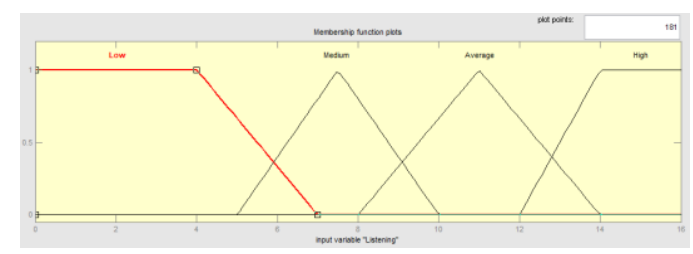

Fig 1. The listening variable membership function curve 
2. Vocabulary Variables

The set of variables can be seen in Table II.

VOCABULARY VARIABLE FUZZY SET

\begin{tabular}{|c|c|}
\hline Linguistic Value & Value Range \\
\hline Low & $0-10$ \\
\hline Medium & $7-15$ \\
\hline Average & $12-21$ \\
\hline High & $19-24$ \\
\hline
\end{tabular}

The curve that is formed to determine the membership function of the vocabulary variable can be seen in Figure 2.

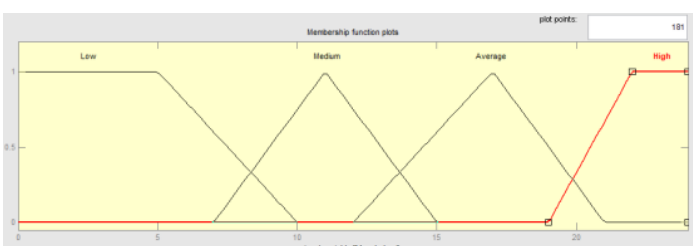

Fig 2 Curve of the vocabulary variable membership function

3. Variable Structure

For the set of variables can be seen in Table 3 .

SET FUZZY VARIABLE STRUCTURE

\begin{tabular}{|c|c|}
\hline Linguistic Value & Value Range \\
\hline Low & $0-10$ \\
\hline Medium & $8-17$ \\
\hline Average & $14-24$ \\
\hline High & $22-28$ \\
\hline
\end{tabular}

The curve that is formed to determine the membership function in the structure variable can be seen in Figure 3.

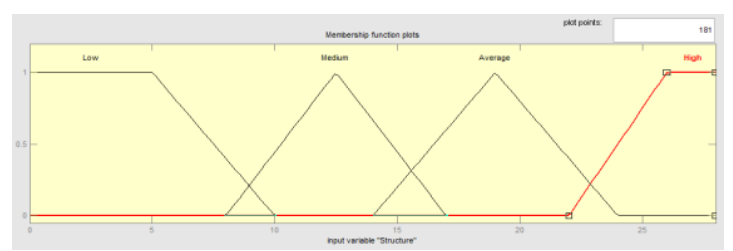

Fig 3 Curve membership function for structure variable

4. Variable Reading

For the set of variables can be seen in Table 4 .

FUZZY VARIABLE READING SET

\begin{tabular}{|c|c|}
\hline Linguistic Value & Value Range \\
\hline Low & $0-12$ \\
\hline Medium & $9-19$ \\
\hline Average & $16-26$ \\
\hline High & $23-32$ \\
\hline
\end{tabular}

The curve that is formed to determine the membership function in the reading variable can be seen in Figure 4.

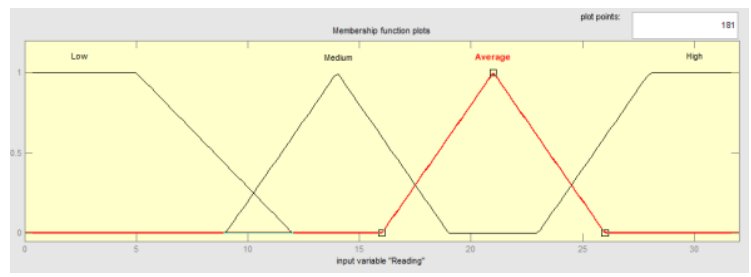

Fig 4 Reading variable membership function curve

5. Output Variables

For the set of output variables can be seen in Table 5

FUZZY SET OF OUTPUT VARIABLES

\begin{tabular}{|c|c|}
\hline Linguistic Value & Value Range \\
\hline Foundation & $0-27$ \\
\hline Basic & $27-50$ \\
\hline Elementary & $50-70$ \\
\hline Intermediate & $70-90$ \\
\hline Advance & $90-100$ \\
\hline
\end{tabular}

The curve that is formed to determine the membership function in the output variable can be seen in Figure 5.

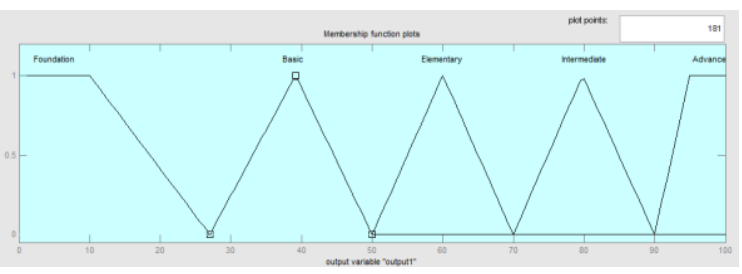

Fig 5 Output variable membership function curve

For each membership function curve, the equation for the membership function for each variable is obtained as follows :

1. The equation for the membership function of the listening variable

$$
\begin{aligned}
& \mu_{\text {Low }}=\left\{\begin{array}{ll}
1, & b \leq x \leq c \\
\frac{7-x}{7-0}, & c \leq x \leq d \\
0, & d \leq x
\end{array} \quad \text { (1) } \mid \mu_{\text {Medium }}= \begin{cases}\frac{1,}{10-x}, & b \leq x \leq d \\
\frac{10-5}{0,} & d \leq x\end{cases} \right. \\
& \mu_{\text {Average }}=\left\{\begin{array}{ll}
1, & b \leq x \leq c \\
\frac{14-x}{14-8}, & c \leq x \leq d \\
0, & d \leq x
\end{array} \quad \text { (3) } \mid \mu_{\text {High }} \quad= \begin{cases}1, & b \leq x \leq c \\
\frac{16-x}{16-12}, & c \leq x \leq d \\
0, & d \leq x\end{cases} \right.
\end{aligned}
$$

2. The equation for the membership function of the vocabulary variable 


$$
\begin{aligned}
& \mu_{\text {Low }} \quad=\left\{\begin{array}{ll}
1, & b \leq x \leq c \\
\frac{10-x}{10-0}, & c \leq x \leq d \\
0, & d \leq x
\end{array} \quad(5) \quad \mu_{\text {Medium }}= \begin{cases}1, & b \leq x \leq c \\
\frac{15-x}{15-7}, & c \leq x \leq d \\
0, & d \leq x\end{cases} \right. \\
& \mu_{\text {Average }}=\left\{\begin{array}{ll}
1, & b \leq x \leq c \\
\frac{21-x}{21-12}, & c \leq x \leq d \\
0, & d \leq x
\end{array} \quad(7) \quad \mu_{\text {High }} \quad= \begin{cases}1, & b \leq x \leq c \\
\frac{24-x}{24-19}, & c \leq x \leq d \\
0, & d \leq x\end{cases} \right.
\end{aligned}
$$

3. The equation for the membership function of the structure variable

$$
\begin{gathered}
\mu_{\text {Low }}=\left\{\begin{array}{ll}
1, & b \leq x \leq c \\
\frac{10-x}{10-0}, & c \leq x \leq d \\
0, & d \leq x
\end{array} \quad \text { (9) } \mid \quad \mu_{\text {Medium }}= \begin{cases}1, & b \leq x \leq c \\
\frac{17-x}{17-8}, & c \leq x \leq d \\
0, & d \leq x\end{cases} \right. \\
\mu_{\text {Average }}=\left\{\begin{array}{ll}
1, & b \leq x \leq c \\
\frac{24-x}{24-14}, & c \leq x \leq d \\
0, & d \leq x
\end{array} \quad \text { (11) } \quad \mu_{\text {High }} \quad= \begin{cases}1, & b \leq x \leq c \\
\frac{28-x}{28-22}, & c \leq x \leq d \\
0, & d \leq x\end{cases} \right.
\end{gathered}
$$

4. The equation for the membership function of the reading variable

$$
\begin{aligned}
& \mu_{\text {Low }}=\left\{\begin{array}{ll}
1, & b \leq x \leq c \\
\frac{12-x}{12-0}, & c \leq x \leq d \\
0, & d \leq x
\end{array} \quad(13) \mid \quad \mu_{\text {Medium }}= \begin{cases}\frac{1,}{19-x}, & b \leq x \leq c \\
\frac{19-9}{0,} & c \leq x \leq d\end{cases} \right. \\
& \mu_{\text {Average }}=\left\{\begin{array}{ll}
1, & d \leq x \leq c \\
\frac{26-x}{26-16}, & c \leq x \leq d \\
0, & d \leq x
\end{array} \quad(15) \mid \mu_{\text {High }} \quad= \begin{cases}\frac{1,}{32-x}, & b \leq x \leq c \\
\frac{32-23}{32} & d \leq x\end{cases} \right.
\end{aligned}
$$

5. The equation for the membership function of the output variable

$$
\begin{aligned}
& \mu_{\text {Foundation }}=\left\{\begin{array}{ll}
1, & b \leq x \leq c \\
\frac{27-x}{27-0}, & c \leq x \leq d \\
0, & d \leq x
\end{array} \quad(17) \quad \mu_{\text {Basic }} \quad= \begin{cases}1, & b \leq x \leq c \\
\frac{50-x}{50-27}, & c \leq x \leq d \quad(18) \\
0, & d \leq x\end{cases} \right.
\end{aligned}
$$

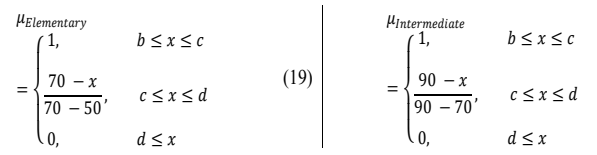

$$
\begin{aligned}
& \mu_{\text {Adtance }} \quad= \begin{cases}1, & b \leq x \leq c \\
\frac{100-x}{100-90,} & c \leq x \leq d \quad(21) \\
0, & d \leq x\end{cases}
\end{aligned}
$$

\section{Fuzzy Rules}

In fuzzy logic, a rule is needed to determine the rules that will be used to calculate the suitability of

\begin{tabular}{|c|c|c|c|c|c|}
\hline Rule & Listening & Vocabulary & Structure & Reading & Output \\
\hline 1 & Low & Low & Low & Low & Foundation \\
\hline 2 & Low & Low & Low & Medium & Foundation \\
\hline 3 & Low & Low & Low & Average & Foundation \\
\hline 4 & Low & Low & Low & High & Foundation \\
\hline 5 & Low & Low & Medium & Low & Foundation \\
\hline 6 & Low & Low & Average & Low & Foundation \\
\hline 7 & Low & Low & High & Low & Foundation \\
\hline 8 & Low & Medium & Low & Low & Foundation \\
\hline 9 & Low & Average & Low & Low & Foundation \\
\hline 10 & Low & High & Low & Low & Foundation \\
\hline 11 & Medium & Low & Low & Low & Foundation \\
\hline 12 & Average & Low & Low & Low & Foundation \\
\hline 13 & High & Low & Low & Low & Foundation \\
\hline 14 & Medium & Medium & Medium & Low & Basic \\
\hline 15 & Medium & Medium & Medium & Medium & Basic \\
\hline 16 & Medium & Medium & Medium & Average & Basic \\
\hline 17 & Medium & Medium & Medium & High & Basic \\
\hline 18 & Medium & Medium & Average & Low & Basic \\
\hline 19 & Medium & Medium & High & Medium & Basic \\
\hline 20 & Medium & High & Medium & Medium & Basic \\
\hline 21 & Average & Medium & Medium & Medium & Basic \\
\hline 22 & High & Medium & Medium & Medium & Basic \\
\hline 23 & Medium & Average & Medium & Medium & Basic \\
\hline 24 & Average & Average & Average & Average & Elementary \\
\hline 25 & Average & Average & Average & High & Elementary \\
\hline 26 & Average & Average & High & Average & Elementary \\
\hline 27 & Average & High & Average & Average & Elementary \\
\hline 28 & High & Average & Average & Average & Elementary \\
\hline 29 & High & Average & Average & High & Intermediate \\
\hline 30 & Average & High & High & Average & Intermediate \\
\hline 31 & Average & Average & High & High & Intermediate \\
\hline 32 & High & High & Average & High & Intermediate \\
\hline 33 & Low & High & High & High & Elementary \\
\hline 34 & High & Low & Low & High & Basic \\
\hline 35 & High & High & High & Average & Advance \\
\hline 36 & High & High & High & High & Advance \\
\hline
\end{tabular}
the results with the fuzzy mamdani method, where the min-max rule applies to this fuzzy method. In this study, the application uses the min rule which means looking for the lowest value in each rule. The fuzzy rules with 36 rules are shown in Table 6.
FUZZY RULES

The process in the matlab application is formulated in Figure 6.

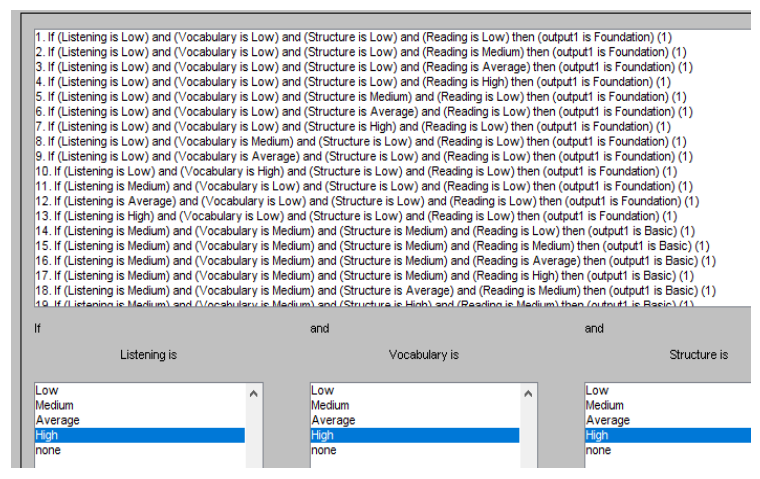

Fig 6 Implementation in the matlab application

\section{Composition of Fuzzy Rules and Defuzzification}

In this research, the fuzzy set solution is obtained by taking the maximum value in the rule rules, then using it to modify the fuzzy area, and applying it to the output.

The defuzzy method to be used is the centroid method. To find the defuzification value, first the moment for each region is calculated. Next, we calculate the area (A) for each region.

The defuzzy method to be used is the centroid method. The results of the calculation of the input listening $=0$, Vocabulary $=0$, Structure $=20$, and Reading $=20$ using Matlab is 50 and is included in the BASIC class category. For more details, it can be seen in Figure 7. 


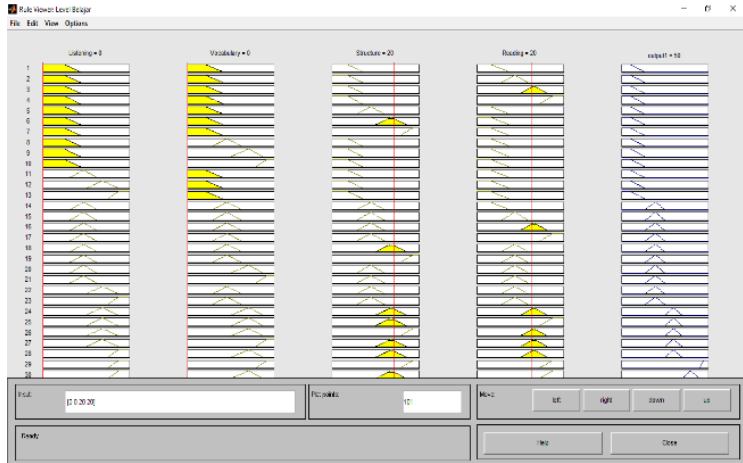

Fig 7 The results of defuzzyfication calculations using Matlab

\section{RESULTS AND DISCUSSION}

In this study, simulating fuzzy calculations using matlab and provided a dataset of student test results that have been carried out at the English course institute. The results of this study will be tested for data accuracy using a Confusion matrix.

\section{Dataset of student exam results}

The following are the results of the dataset that have been simulated using Matlab to recommend a suitable learning level for students according to the test results in table 7, 1 (Listening), 2 (Vocabulary), 3 (Structure), 4 (Reading).

\section{DATASET OF STUDENT EXAM RESULTS}

\begin{tabular}{|c|c|c|c|c|c|}
\hline No & $\mathbf{1}$ & $\mathbf{2}$ & $\mathbf{3}$ & $\mathbf{4}$ & Learning Level \\
\hline 1 & 16 & 24 & 28 & 32 & ADVANCE \\
\hline 2 & 8 & 16 & 22 & 24 & BASIC \\
\hline 3 & 0 & 12 & 20 & 20 & BASIC \\
\hline 4 & 8 & 15 & 28 & 24 & BASIC \\
\hline 5 & 16 & 2 & 22 & 24 & BASIC \\
\hline 6 & 8 & 17 & 22 & 24 & BASIC \\
\hline 7 & 16 & 13 & 28 & 24 & INTERMEDIATE \\
\hline 8 & 16 & 16 & 22 & 24 & ELEMENTARY \\
\hline 9 & 11 & 15 & 28 & 24 & ELEMENTARY \\
\hline 10 & 8 & 20 & 22 & 24 & ELEMENTARY \\
\hline 11 & 16 & 24 & 28 & 32 & ADVANCE \\
\hline 12 & 8 & 16 & 22 & 24 & ELEMENTARY \\
\hline 13 & 0 & 12 & 20 & 20 & BASIC \\
\hline 14 & 5 & 15 & 28 & 24 & ELEMENTARY \\
\hline 15 & 16 & 16 & 22 & 24 & ELEMENTARY \\
\hline 16 & 8 & 17 & 22 & 24 & ELEMENTARY \\
\hline 17 & 16 & 13 & 28 & 24 & INTERMEDIATE \\
\hline 18 & 16 & 16 & 22 & 24 & ELEMENTARY \\
\hline 19 & 16 & 24 & 28 & 32 & ADVANCE \\
\hline 20 & 4 & 20 & 22 & 24 & BASIC \\
\hline
\end{tabular}

\begin{tabular}{|c|c|c|c|c|c|}
\hline No & $\mathbf{1}$ & $\mathbf{2}$ & $\mathbf{3}$ & $\mathbf{4}$ & Learning Level \\
\hline 21 & 16 & 24 & 28 & 32 & ADVANCE \\
\hline 22 & 8 & 16 & 22 & 24 & ELEMENTARY \\
\hline 23 & 0 & 12 & 20 & 20 & BASIC \\
\hline 24 & 4 & 15 & 28 & 24 & ELEMENTARY \\
\hline 25 & 16 & 24 & 28 & 32 & ADVANCE \\
\hline 26 & 7 & 17 & 22 & 24 & ELEMENTARY \\
\hline 27 & 16 & 13 & 28 & 24 & INTERMEDIATE \\
\hline 28 & 16 & 16 & 22 & 24 & ELEMENTARY \\
\hline 29 & 11 & 15 & 28 & 24 & ELEMENTARY \\
\hline 30 & 8 & 20 & 22 & 24 & ELEMENTARY \\
\hline 31 & 16 & 24 & 28 & 32 & ADVANCE \\
\hline 32 & 8 & 16 & 22 & 24 & ELEMENTARY \\
\hline 33 & 0 & 12 & 20 & 20 & BASIC \\
\hline 34 & 8 & 15 & 28 & 24 & BASIC \\
\hline 35 & 16 & 9 & 22 & 24 & BASIC \\
\hline 36 & 8 & 17 & 22 & 24 & ELEMENTARY \\
\hline 37 & 16 & 13 & 28 & 24 & INTERMEDIATE \\
\hline 38 & 16 & 16 & 22 & 24 & ELEMENTARY \\
\hline 39 & 11 & 15 & 28 & 24 & ELEMENTARY \\
\hline 40 & 8 & 20 & 22 & 24 & ELEMENTARY \\
\hline 41 & 11 & 15 & 28 & 24 & ELEMENTARY \\
\hline 42 & 8 & 20 & 22 & 24 & ELEMENTARY \\
\hline 43 & 16 & 24 & 28 & 32 & ADVANCE \\
\hline 44 & 8 & 16 & 22 & 24 & ELEMENTARY \\
\hline 45 & 0 & 12 & 20 & 20 & BASIC \\
\hline 46 & 7 & 15 & 28 & 24 & BASIC \\
\hline 47 & 16 & 16 & 22 & 24 & ELEMENTARY \\
\hline 48 & 8 & 17 & 22 & 24 & ELEMENTARY \\
\hline 49 & 16 & 13 & 28 & 24 & INTERMEDIATE \\
\hline 50 & 16 & 16 & 22 & 24 & ELEMENTARY \\
\hline
\end{tabular}

\section{Data accuracy testing}

Testing the results of the test is by using confusion matrix where from 50 students 10 samples are taken and made into a dataset, while 40 are used as training data with cross-validation 10 times, and the result is $88 \%$ declared accurate. For clarity in Figure 8. 


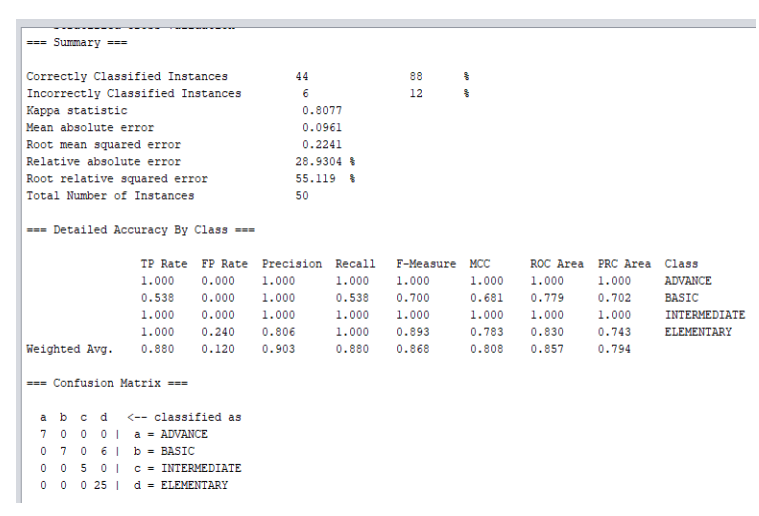

Fig 8 The results of the student score dataset test with confusion matrix

\section{CONCLUSIONS}

The results of the research with Fuzzy Logic for Learning Level Recommendations after being tested for validation were able to recommend the level of learning English with data accuracy of $88 \%$. Test the results of the recommendations using confusion atrix. For further research it is recommended to use a method other than fuzzy, other intelligent algorithms can be used.

\section{REFERENCES}

Aly, W. M., Eskaf, K. A., \& Selim, A. S. (2017). Fuzzy mobile expert system for academic advising. Canadian Conference on Electrical and Computer Engineering. https://doi.org/10.1109/CCECE.2017.7946846

Cibira, G., \& Dulik, M. (2016). Fuzzy logic routing within international academic networks. ELEKTRO 2016 - 11th International Conference, Proceedings, 36-41. https://doi.org/10.1109/ELEKTRO.2016.7512 031

Efendi, D. M. (2019). Implementasi Logika Fuzzy Mamdani Pada Sistem Rekomendasi Perpanjangan Kontrak Kerja Karyawan.
JATISI (Jurnal Teknik Informatika Dan Sistem Informasi), $\quad 6(1), \quad$ 106-115. https://doi.org/10.35957/jatisi.v6i1.169

Hameed, I. A. (2016). A simplified implementation of interval type-2 fuzzy system and its application in students' academic evaluation. 2016 IEEE International Conference on Fuzzy Systems, FUZZ-IEEE 2016, 650-656. https://doi.org/10.1109/FUZZIEEE.2016.7737748

Hameed, I. A. (2017). Enhanced fuzzy system for student's academic evaluation using linguistic hedges. IEEE International Conference on Fuzzy Systems. https://doi.org/10.1109/FUZZIEEE.2017.8015462

Rahman, A., Mutiarawan, R. A., Darmawan, A., Rianto, Y., \& Syafrullah, M. (2019). Prediction of students academic success using case based reasoning. International Conference on Electrical Engineering, Computer Science and Informatics (EECSI), 171-176.

https://doi.org/10.23919/EECSI48112.2019.89 77104

Rao, D. H., Mangalwede, S. R., \& Deshmukh, V. B. (2018). Student performance evaluation model based on scoring rubric tool for network analysis subject using fuzzy logic. International Conference on Electrical, Electronics, Communication Computer Technologies and Optimization Techniques, ICEECCOT 2017, 2018-Jапиа, 857-861. https://doi.org/10.1109/ICEECCOT.2017.8284 623

Sutrisno, M., \& Budiyanto, U. (2019). Intelligent System For Recommending Study Level in English Language Course Using CBR Method. International Conference on Electrical Engineering, Computer Science and Informatics (EECSI), 153-158. 